\title{
Assessing the links between childhood trauma, C-reactive protein and response to antidepressant treatment in patients with affective disorders
}

\author{
Kai F. Fischer ${ }^{1}$ - Maria S. Simon ${ }^{1}$. Julie Elsner ${ }^{3}$. Johanna Dobmeier ${ }^{4} \cdot$ Johannes Dorr $^{5} \cdot$ Leonie Blei $^{1} \cdot$ Peter Zill $^{1}$. \\ Michael Obermeier $^{2} \cdot$ Richard Musil $^{1}$
}

Received: 8 July 2020 / Accepted: 24 February 2021 / Published online: 17 March 2021

(c) The Author(s) 2021

\begin{abstract}
Adverse Childhood Experiences (ACE) are a well-known risk-factor for depression. Additionally, (high-sensitive) C-reactive Protein (hsCRP) is elevated in subgroups of depressed patients and high following ACE. In this context the literature considers hsCRP and ACE to be associated with treatment resistant depression. With the data being heterogenous, this study aimed to explore the associations of ACE, hsCRP levels and response to antidepressant treatment in uni- and bipolar depression. $N=76$ patients diagnosed with uni- or bipolar depression and $N=53$ healthy controls were included. Treatment was over 6 weeks in an inpatient psychiatric setting within an observatory study design. Depressive symptoms were assessed by the Montgomery-Asberg Depression Rating Scale (MADRS), ACE were assessed by the Childhood Trauma Questionnaire (CTQ); the body-mass-index (BMI) and hsCRP were measured. HsCRP levels did not differ between the study population and the healthy controls. While the depressive symptoms decreased, the hsCRP levels increased. Sexual abuse was associated with significant higher and emotional abuse with lower levels of hsCRP after 6 weeks. The baseline hsCRP levels and the ACE subgroups did not show significant associations with the treatment response in unipolar depressed patients. The long-lasting effects of specific forms of ACE may have relevant impact on inflammation, supporting hsCRP to be a suitable biomarker. With ACE and hsCRP not showing any significant associations with treatment response in the unipolar depressed subgroup, a more differentiate research concerning biomarkers and treatment regimens is needed when talking about treatment response.
\end{abstract}

Keywords Childhood trauma $\cdot$ Inflammation $\cdot$ CRP $\cdot$ Depressive disorder $\cdot$ Treatment resistance

\section{Introduction}

Kai F. Fischer

kai.fischer@med.uni-muenchen.de

1 Department of Psychiatry and Psychotherapy, University Hospital, LMU Munich, Nußbaumstraße 7, 80336 München, Germany

2 GKM Gesellschaft für Therapieforschung mbH, Munich, Germany

3 Institute of Mental Health at UBC, University of British Columbia, Vancouver, Canada

4 Endopraxis Amberg, Amberg, Germany

5 Clinic for Internal Medicine South, Munich, Germany
Early life stress is among the most important risk factors for physical and mental health problems [2, 22, 24, 39, 53, 60]. Adverse Childhood Experiences (ACE), such as emotional abuse and neglect, physical abuse and neglect and sexual abuse, are more frequent in numerous psychiatric diseases $[2,3,13,26,53]$. ACE are furthermore associated with a worse clinical course [20,68], higher rates of suicide attempts [2], recurrent episodes [58] and treatment resistance [77] within uni- and bipolar depression.

But also chronic somatic diseases like Diabetes mellitus or coronary heart disease, who are amongst the leading causes of death $[4,33,41,53]$ are all more often after ACE. Evident underlying pathogenetic mechanisms are increased incidences of traditional risk factors such as smoking, overeating or alcohol abuse (e.g., [21, 72]) used as dysfunctional 
coping strategies to regulate aversive emotions [53]. Furthermore, literature suggests ACE to be a risk factor themselves by causing structural and functional brain alterations (e.g., $[62,82])$ as well as a chronic state of inflammation induced by long-lasting psychological stress [23].

In the early stages of life, human sensitivity to stress is particularly high. Enduring toxic stress exceeds the child's abilities to cope and leads to a dysregulation of the central biological stress pathway, the hypothalamus-pituitary-adrenal (HPA) axis and an alteration of the human's autonomic nerval system and immune system [61]. Over time this may cause epigenetic changes in stress-response-genes such as FKBP5 [83] or the monoamine-oxidase-gene [10]. Besides a low heritability, gene-environment interactions through epigenetic alterations are suspected of carrying on the effects of ACE up to adulthood (for an overview see Ref. [38]). As a possible result, people with ACE often find themselves in a chronic state of inflammation [15]. In this context, (highsensitive) C-reactive protein (hsCRP) is one potential and promising biomarker [7, 17, 18]. Beside the established elevation in obese people [14], recent literature identified higher levels of hsCRP in mental ill and healthy people with a history of ACE [7, 15, 18, 48, 63]. However, when differentiating ACE into single forms of maltreatment, current literature is still heterogenous. While Baumeister et al. [7] and Moraes et al. [56] highlight the relevance of sexual and physical abuse in consecutive inflammatory processes, other authors do not differ between single forms of ACE [15, 19].

Along with ACE, inflammation is discussed to play also an important role in the development of uni- and bipolar depression $[65,69,71,80]$. While underlying mechanisms remain uncertain, literature indicates that inflammation markers, such as IL-6, TNF- $\alpha$ or hsCRP are elevated in subgroups of patients with uni- and bipolar depression and increase the risk for developing a major depression in healthy adults $[12,19,31,65,74,79-81]$.

Amongst evolutionary and biological models (for an overview see Ref. [52]), numerous authors support the hypothesis of multifactorial sequential pathways from enduring stress arising from ACE, epigenetic alterations, dysfunctional coping strategies and inflammation to depression [1, $30,63,74]$.

The inflammation hypothesis of depression furthermore suggests elevated inflammation markers to play a key role in the course and response to anti-depressant treatment $[12,71]$. Current research focuses on the question whether inflammation markers can predict anti-depressant therapy response with suggesting higher inflammation to be associated with worse response [5, 12, 49]. A recent review of Arteaga-Henriquez et al. [5] stated that the neurotransmitter systems (serotonin, noradrenaline, dopamine) targeted by an anti-depressant drug are crucial for the response. Depressed patients with a low-grade inflammation (hsCRP levels $<1 \mathrm{mg} / \mathrm{l})$ seem to already profit from first-line serotonergic substances, while add-on dopaminergic, noradrenergic and glutamatergic as well as add-on anti-inflammatory medication are associated with better response rates in patients with higher hsCRP levels $>1 \mathrm{mg} / \mathrm{l}$. In this context, data concerning the alteration of the potential biomarkers during a depressive episode and therefore their ability to indicate an amelioration is very heterogenous in current literature [49, 76]. For a better understanding of the underlying mechanisms in the development of depression and the long-lasting effects of ACE, as well as in the search for new treatment strategies in depression the associations of ACE, inflammation and treatment response appear to play an important role.

Therefore, the present study aims to explore first, whether different forms of ACE are associated with altered hsCRP levels, second, if specific forms of ACE are associated with the response to anti-depression treatment, third, whether the treatment response is also associated with hsCRP levels, and fourth, whether the hsCRP levels vary during anti-depressant treatment.

\section{Methods}

\section{Study design}

We analysed data from an observational prospective clinical trial with a naturalistic design conducted in the Department of Psychiatry and Psychotherapy of the University Hospital Munich (Ludwig-Maximilians-Universität München). There were no constraints concerning the applied medication. After inclusion, the drugs prescribed were chosen according to clinical experience and in consideration of the recommendations of the national guideline for uni- and bipolar depression. Besides pharmacological treatment, therapy included a multidisciplinary treatment consisting of ergoand physiotherapy as well as a regular psychoeducation group based on cognitive-behavioural therapy. The study duration was 6 weeks after admission to the hospital. All procedures were approved by an independent local ethics committee and the study was conducted according to the criteria for Good Clinical Practice as well as to the Declaration of Helsinki in its last revision.

\section{Study population}

$N=76$ patients who met the diagnostic criteria for unior bipolar depression (F31.x, F32.x, F33.x) according to the International Cluster of Differentiation (ICD-10) were included. Further inclusion criteria were an age of 18-65 years and written informed consent. Exclusion criteria were an ongoing substance abuse (except for nicotine), a relevant physical disease, a co-morbid personality disorder 
(F60.x), a maniac episode (F31.0, F31.1) and a diagnosis out of the schizophrenia spectrum (F20.x).

The healthy control group $(N=53)$ was matched to the study group in terms of age. With a structured interview, the control subjects were screened for a history of or present psychiatric disorder. Depressive symptoms were screened using the Beck Depression Inventory (BDI) [8, 43]. To fulfil inclusion criteria for the healthy control group, an absence of a psychiatric diagnosis and a total BDI score $<10$ were necessary.

\section{Assessments}

To assess the severity of depressive symptoms and for a sufficient comparability the Montgomery-Asberg Depression Rating Scale (MADRS) [54, 67], the Hamilton Depression Rating Scale (HAMD) in its 21 item version [28] and the self-measurement questionnaire Beck Depression Inventory (BDI) [43] were applied. All three represent well-validated and established instruments in assessing depressive symptoms.

Concerning the ACE, the Childhood Trauma Questionnaire (CTQ) [78] was used. The CTQ is a 28-item self-report questionnaire assessing five subscales of childhood maltreatment retrospectively: emotional abuse and neglect, physical abuse and neglect and sexual abuse. The subscales are measured on a 5-point Likert scale with the range from 1 (never true) to 5 (very often true). Three minimization or denial items are also part of the questionnaire. For the subscales and the total trauma burden scores can be calculated; it is also possible to make a categorial evaluation with a "exist" or "doesn't exist" statement for each form of childhood maltreatment. The Questionnaire demonstrates good validity and reliability (cronbach's alpha 0.95 , intra-class correlation 0.88) [9]. In the present study, we used the German version of the CTQ [78]. All ratings were performed by trained rater. At baseline, socio-demographic variables and the CTQ were assessed, BMI $\left(\mathrm{kg} / \mathrm{m}^{2}\right)$ was calculated. MADRS-, HAMD- and BDI-scores were rated at baseline, and after 2 and 6 weeks.

For measuring high-sensitive CRP, peripheral blood samples were collected at baseline and additionally after 6 weeks in the study population. Analysis were performed by the Laboratory for Psychiatric Genetic and Neurochemistry in the Department of Psychiatry and Psychotherapy of the University Hospital Munich (Ludwig-MaximilliansUniversität München). After centrifugation with $1500 \mathrm{~g}$ for 4 min at $4{ }^{\circ} \mathrm{C}$, hsCRP was assessed in EDTA-plasma with a commercially available ELISA Kit (Human High Sensitivity C-Reactive Protein; hsCRP, Cusabio, Houston, USA). Detection was conducted on the Polarstar Optima Plate Reader (BMG Labtech, Ortenberg, Deutschland).

\section{Statistics}

For identifying group differences between the healthy control group and the study population as well as for differentiating the early-improver/responder subgroup concerning hsCRP and to analyse the course of the depressive symptoms in the unipolar depression subgroup ( $\triangle$ MADRS, $\triangle$ HAMD, $\triangle B D I$ ), non-parametric tests (Wilcoxon test, Man-Whitney $U$ test) were performed.

To analyse the association between ACE and hsCRP, multiple regression analysis were performed under correction of the BMI and smoking state as a confounder of inflammation. For the calculations, hsCRP was $\log 10$ transformed due to concerning residual plots for the final models without log transformation.

To analyse the association between ACE, hsCRP and treatment response, multiple regression analysis were performed under correction of the BMI and the state concerning recurrent depression as well know confounder for Inflammation, respectively, treatment response. Due to the ongoing discussion of the use of antidepressants in bipolar disorder the patients with a bipolar depression were excluded from the analyses concerning treatment response.

For the multiple regression analysis, we used the total scores of the MADRS and the subscales of the CTQ. To increase sensitivity, we refrained from including continuous (total number) and dichotomous (exposed vs. not exposed) measures for the childhood adversities. To measure response to antidepressant treatment, $\triangle M A D R S \_l$ was calculated by the difference between the MADRS total score at baseline minus the MADRS total score after 2 weeks. For building subgroups, early improvement was defined as a $20 \%$ reduction of the baseline MADRS Score after 2 weeks. $\triangle M A D R S \_2$ was calculated as the difference between MADRS total score at baseline minus the MADRS total score after 6 weeks. At the end of the study period responder state was defined as a minimum reduction of $50 \%$ of the MADRS total score at baseline.

When the statistical calculations were performed levels of hsCRP $>10 \mathrm{mg} / \mathrm{l}$ were excluded. We ran the statistical analysis without probands above this stated threshold to avoid acute infections or physical injury being responsible for elevated inflammation markers. This threshold is recommended by the U. S. Centers for Disease Control and Prevention and the American Heart Association.

To verify the model condition of normal distributed residuals, residual plots of the final models were compiled. All results were corrected for multiple testing via the Bonferroni correction. To ensure a global level of significance of $p<0.05$, the threshold for each variable in the multiple regression analysis was set at $p<0.0071$. The statistical analyses were performed with SPSS 25.0 [70]. 


\section{Results}

Study population and test persons in the healthy control group were matched concerning age and sex. The mean BMI in the study population lay just below the limit of pre-obesity (defined as $>25 \mathrm{~kg} / \mathrm{m}^{2}$ according to ICD-10) and the majority was diagnosed with a unipolar depression (89.5\%). After 6 weeks $N=9$ patients were excluded from the statistical analyses due to missing data.

Table 1 summarizes the demographic characteristics of the study population and the data of the healthy control group. It also shows the results of the blood samples, Table 2 summarizes the total scores of the questionnaires.

The majority of the study population took anti-depressive medication when being admitted to the hospital. Only $11.3 \%$ of the probands did not take any psychopharmacologic drugs, whereas almost half of the study population $(46.5 \%)$ received a combined therapy consisting of a combination of two or more antidepressants or an augmentation of an antidepressant with an atypical antipsychotic drug. $44.7 \%$ of the patients took either benzodiazepines or zopiclone when included in the study. Table 3 summarizes the prescribed medication at baseline.

\section{HsCRP sample characteristics}

HsCRP levels in the study population $(m=1.63, \mathrm{SD}=2.48)$ did not differ significantly from the healthy controls $(m=1.30, \mathrm{SD}=1.46)$ at baseline $(U=1890.5, z=0.592$, $r=0.05, p=0.810$ ). Within the subgroups of the study population, neither the early-improvement $(U=733.5, z=0.340$, $r=0.05, p=0.734)$ nor the responder state $(U=706.5$, $z=0.840, r=0.05, p=0.401)$ showed significant differences

Table 1 Demographics of study population and control group

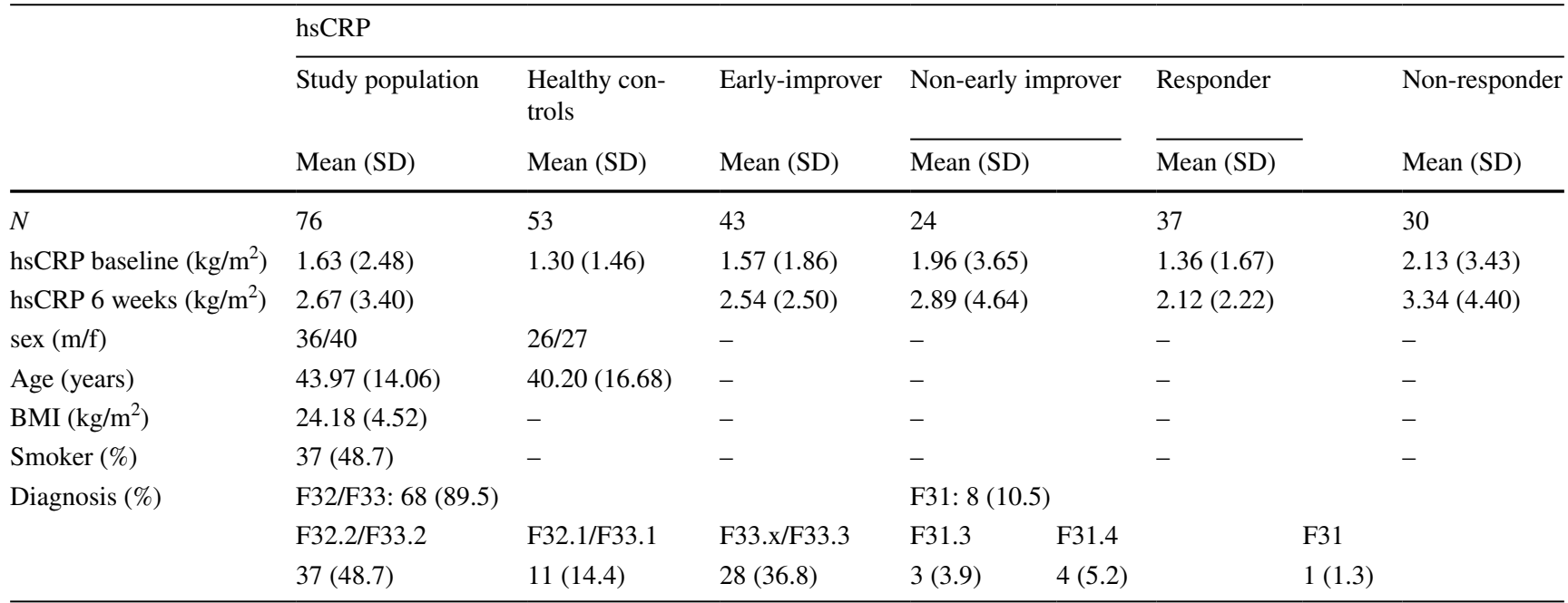

Table 2 Scales for depression and childhood trauma

\begin{tabular}{|c|c|c|c|c|}
\hline \multicolumn{5}{|l|}{ Depression } \\
\hline & MADRS m (SD) & HAMD m (SD) & & BDI m (SD) \\
\hline Baseline & $26.00(7.32)$ & $26.64(7.02)$ & & $46.67(9.00)$ \\
\hline 2 weeks & $17.46(9.44)$ & $17.84(8.69)$ & & $39.91(9.78)$ \\
\hline 6 weeks & $12.90(7.89)$ & $13.34(7.71)$ & & $30.50(13.61)$ \\
\hline \multicolumn{5}{|c|}{ Childhood Trauma Questionnaire } \\
\hline Subscale & Total score (SD) & & Prevalence $(\%)$ & \\
\hline Emotional abuse & $9.57(5.65)$ & & $19(25)^{\mathrm{a}}$ & \\
\hline Emotional neglect & $12.12(5.51)$ & & $47(61.8)^{\mathrm{a}}$ & \\
\hline Physical abuse & $6.61(3.17)$ & & $9(11.8)^{\mathrm{a}}$ & \\
\hline Physical neglect & $7.66(3.5)$ & & $16(21.1)^{\mathrm{a}}$ & \\
\hline Sexual abuse & $6.54(4.21)$ & & $10(13.2)^{\mathrm{a}}$ & \\
\hline
\end{tabular}

${ }^{\text {a}}$ Prevalence of the forms of childhood maltreatment equate total scores in the range of moderate to severe and severe to extreme abuse in the CTQ 
Table 3 Medication of the study population at baseline

\begin{tabular}{|c|c|c|c|c|c|c|c|c|c|}
\hline & Combined & herapy + se & atives & Combined therapy - sedat & & Monotherapy SSRI & & Untreated & \\
\hline \multirow[t]{2}{*}{$N(\%)$} & $47(66.2)$ & & & $33(46.5)$ & & $8(11.3)$ & & $8(11.3)$ & \\
\hline & & SSRI & SNRI & Mirtazapine & TCA & MAO-I & Sedatives & & AAP \\
\hline$N(\%)$ & & $32(45.1)$ & $10(14.1)$ & $10(14.1)$ & $9(12.7)$ & $6(8.5)$ & $34(44.7)$ & & $25(35.2)$ \\
\hline
\end{tabular}

Sedatives benzodiazepines, zopiclone, SSRI selective serotonin reuptake inhibitor, SNRI serotonin noradrenaline reuptake inhibitor, TCA tricyclic antidepressants, $M A O-I$ monoamine oxidase inhibitor, $A A P$ atypical antipsychotic, $M S$ mood stabilizer

compared to hsCRP levels in the healthy controls. Concerning the early improvement state (early vs. non-early improvement after 2 weeks) in the unipolar depression group, the subgroups did not show significant differences regarding baseline hsCRP $(U=523.5, z=0.58, r=0.05, p=0.954)$. The same applies to the hsCRP levels at the beginning of the study when stratifying the study population into responder/non-responder state after 6 weeks $(U=375.5$, $z=0.89, r=0.05, p=0.374)$. At the end of the treatment period, statistical analysis showed a significant increase of hsCRP levels in the overall study population ( $m=2.67$, SD $3.40, z=3.30, r=0.40, p=0.001)$.

\section{ACE in the study population}

The most frequently reported types of ACE were emotional neglect with $61.8 \%$ prevalence rates in the study population, followed by emotional abuse (25\%) and physical neglect (21.1\%). Sexual and physical abuse were the least frequent but still reported by over $10 \%$ of the study population (see Table 2).

\section{Symptom decrease over treatment time}

The total scores of the depression self-questionnaire (BDI, $Z=6.847, r=0.05, p=0.000$ ) and the two physician administered questionnaires (MADRS, $Z=6.394, r=0.05$, $p=0.000$; HAMD, $Z=6.405, r=0.05, p=0.000)$ significantly decreased during the treatment period. While the mean of the MADRS score indicates moderate depression at baseline, the mean HAMD value equates severe depression. Both questionnaires result in means indicating mild depression after 6 weeks. By contrast, the BDI still reports severe depression at the end of treatment (see Table 2).

\section{ACE and inflammation}

The multiple regression analysis showed no significant associations of the total scores of the CTQ subscales with higher levels of loghsCRP at baseline and after correction for multiple testing. Smoking state showed also no significant associations with the baseline loghsCRP.

When looking at the loghsCRP after 6 weeks sexual abuse $(\beta=0.330, p=0.007)$ and the BMI $(\beta=0.427, p=0.000)$ showed significant positive associations. The subscale emotional abuse showed a significant negative correlation with $\operatorname{loghs} \mathrm{CRP}(\beta=-0.589, p=0.000)$. Furthermore, the BMI

Table 4 Multiple regression for loghsCRP with CTQ subscales, BMI and smoking state

\begin{tabular}{|c|c|c|c|c|c|c|c|c|c|c|c|}
\hline & \multicolumn{6}{|c|}{ loghsCRP (baseline) } & \multicolumn{5}{|c|}{ loghsCRP (6 weeks) } \\
\hline & $\beta$ & Stand $\beta$ & $p$ & $95 \% \mathrm{CI}$ & & & $\beta$ & Stand $\beta$ & $p$ & $95 \% \mathrm{Cl}$ & \\
\hline Emotional abuse & -0.030 & -0.328 & 0.049 & 0.049 & -0.061 & & -0.057 & -0.589 & $0.000^{*}$ & -0.087 & -0.026 \\
\hline Emotional neglect & 0.022 & 0.231 & 0.012 & -0.006 & & 0.050 & 0.031 & 0.326 & 0.027 & 0.004 & 0.059 \\
\hline Physical abuse & -0.020 & -0.122 & 0.401 & -0.068 & & 0.028 & -0.025 & -0.146 & 0.328 & -0.077 & 0.026 \\
\hline Physical neglect & 0.030 & 0.193 & 0.193 & -0.190 & & 0.079 & 0.055 & 0.343 & 0.031 & 0.005 & 0.015 \\
\hline Sexual abuse & 0.036 & 0.231 & 0.017 & 0.007 & & 0.065 & 0.040 & 0.330 & $0.007 *$ & 0.011 & 0.068 \\
\hline BMI & 0.060 & 0.490 & $0.000^{*}$ & 0.034 & 0.085 & & 0.050 & 0.427 & $0.000^{*}$ & 0.025 & 0.075 \\
\hline Smoker & 0.147 & 0.140 & 0.181 & -0.070 & 0.363 & & 0.178 & 0.169 & 0.112 & -0.43 & 0.399 \\
\hline$F$ & \multicolumn{6}{|c|}{$4.743^{*}(d f=7 ; 70)$} & \multicolumn{5}{|c|}{$5.817 *(d f=7 ; 62)$} \\
\hline$R^{2}$ & \multicolumn{6}{|c|}{0.345} & \multicolumn{5}{|c|}{0.425} \\
\hline Corrected $R^{2}$ & \multicolumn{6}{|l|}{0.272} & \multicolumn{5}{|l|}{0.352} \\
\hline
\end{tabular}

${ }^{*} p<0.05$ (for a global level of significance after correction for multiple testing via Bonferroni correction, equates a level of significance of $p<0.0071$ for each variable) 
was positively associated with loghsCRP regardless the decrease of the depressive symptoms (see Table 4).

\section{Treatment response in relation to $\mathrm{ACE}$ and inflammation}

Finally, the multiple regression analysis for the treatment response after 2 weeks $\left(\triangle M A D R S_{-} 1\right)$ showed no significant associations with none of the CTQ subscales nor the level of hsCRP at baseline under control of the $\mathrm{BMI}$ and the patient's state concerning first/recurrent depressive episode. When setting the treatment response after 6 weeks ( $\left.\triangle M A D R S \_2\right)$ as dependent variable, the statistics showed no significant associations as well (see Table 5).

\section{Discussion}

\section{Summary}

To our knowledge, this is the first study exploring the associations between specific forms of ACE, hsCRP and response to antidepressant treatment in patients diagnosed with uni- or bipolar depression. HsCRP levels in the overall study population, in the subgroups early-improver and responder did not significantly differ from the healthy control group. Multiple regression analysis showed that a higher BMI was significantly associated with higher levels of hsCRP at baseline, while the smoking status and the
CTQ subscales did not. After 6 weeks of anti-depressant treatment with a significant decrease of the depressive symptoms and a significant increase of the hsCRP levels, the BMI and sexual abuse was associated with significant higher levels of hsCRP. While emotional abuse was associated with significant lower levels of hsCPR, the remaining CTQ subscales did not show any significant associations with the inflammation marker after correction for multiple testing. Concerning treatment response after 2 and 6 weeks, the statistical analyses showed no significant associations whether with the CTQ subscales nor with the hsCRP levels at baseline. The level of the inflammation marker at baseline did not significantly differ in the retrospectively built early-improver/non-early-improver or responder/non-responder state subgroups.

\section{ACE and hsCRP}

Along with a growing amount of literature, the findings in our studies support the hypothesis of a long-lasting effect on the inflammation process following ACE [7, 15, 48]. The most suitable parameters for showing chronic inflammation after ACE remain unclear although hsCRP, IL-6 and TNFalpha are being discussed as potential candidates [7, 57]. While the meta-analysis of Baumeister et al. [7] emphasises higher levels of TNF- $\alpha$ and IL- 6 after physical and sexual abuse, they didn't find this association for hsCRP. By contrast and along with our findings, more recent studies showed higher hsCRP levels after sexual abuse [1,56] while other studies found similar associations after one or more ACE (without specifying the kind of trauma) $[6,48]$. A study by Aas et al. [1] found higher levels of hsCRP in

Table 5 Multiple regression analysis for $\triangle M A D R S$ with CTQ, BMI, hsCRP and recurrent depression

\begin{tabular}{|c|c|c|c|c|c|c|c|c|c|c|}
\hline & \multicolumn{5}{|c|}{$\Delta$ MADRS_1 } & \multicolumn{5}{|c|}{$\Delta$ MADRS_2 } \\
\hline & $\beta$ & Stand $\beta$ & $p$ & $95 \% \mathrm{CI}$ & & $\beta$ & Stand $\beta$ & $p$ & $95 \% \mathrm{CI}$ & \\
\hline Emotional abuse & -0.442 & -0.304 & 0.151 & -1.051 & 0.167 & -0.567 & -0.324 & 0.167 & -1.382 & 0.247 \\
\hline Emotional neglect & 0.519 & 0.350 & 0.061 & -0.024 & 1.062 & 0.487 & 0.284 & 0.165 & -0.208 & 1.182 \\
\hline Physical abuse & 0.310 & 0.102 & 0.561 & -0.752 & 1.371 & 0.827 & 0.216 & 0.301 & -0.765 & 2.420 \\
\hline Physical neglect & 0.006 & 0.003 & 0.089 & -0.945 & 0.0958 & -0.077 & -0.260 & 0.903 & -1.351 & 1.197 \\
\hline Sexual abuse & -0.613 & -0.249 & 0.091 & -1.325 & 0.100 & -0.387 & -0.139 & 0.392 & -1.289 & 0.515 \\
\hline hsCRP & -1.264 & -0.245 & 0.107 & -2.813 & 0.284 & -1.586 & -0.276 & 0.114 & -3.569 & 0.397 \\
\hline Recurrent Episode & 3.642 & -0.245 & 0.107 & -2.813 & 8.611 & 2.563 & 0.116 & 0.452 & -4.250 & 9.376 \\
\hline BMI & -0.026 & -0.14 & 0.927 & -0.585 & 0.534 & -0.003 & -0.001 & 0.993 & -0.717 & 0.711 \\
\hline$F$ & $(d f=8 ; 60)$ & \multicolumn{4}{|c|}{$1.626(\operatorname{sig} 0.14)$} & $(d f=8 ; 52)$ & \multicolumn{4}{|c|}{0.882 (sig 0.539$)$} \\
\hline$R^{2}$ & \multicolumn{5}{|l|}{0.200} & \multicolumn{5}{|l|}{0.138} \\
\hline Corrected $R^{2}$ & \multicolumn{5}{|l|}{0.077} & \multicolumn{5}{|l|}{-0.019} \\
\hline
\end{tabular}

$p<0.05 ; \Delta$ MADRS_1=MADRS (baseline) - MADRS (2 weeks), $\Delta$ MADRS_2=MADRS (baseline) - MADRS (6 weeks)

$p<0.05$ (for a global level of significance after correction for multiple testing via Bonferroni correction, equates a level of significance of $p<0.0063$ for each variable) 
healthy controls as well as in a bipolar and schizophrenia mixed sample after childhood maltreatment but only before controlling for BMI.

With emotional abuse being associated with lower levels of hsCRP and sexual abuse showing higher hsCPR levels in the present population after the decrease of depressive symptoms, the question of why different types of ACE seem to have a different impact on inflammatory regulation processes becomes more and more urgent and should be considered in future research [7].

As stated before, the current literature is still heterogenous [7]. Our findings contribute to the heterogeneity of the available data with supporting the hypotheses of the long lasting effects of ACE on the human immune system. Especially the finding, that after a decrease of the depressive symptoms after 6 weeks, the associations of ACE and hsCRP became visible (for emotional abuse and sexual abuse), suggest both the influences of depression on hsCRP as well as the enduring impact of ACE. When looking at the CTQ subscales sexual abuse and emotional neglect at baseline as well as emotional and physical neglect after the treatment period, the multiple regression analysis showed significant positive correlations with hSCRP but only before correction for multiple testing. Here, more definite results would be eligible in further studies. Possible underlying molecular mechanisms are the subject of current research focusing on epigenetic regulation of gene expression (e.g., glucocorticoid receptor, FKBP5) and modifications of the hypothalamus-pituitary-adrenocortical axis [44, 50, 51].

\section{ACE and depression}

In line with other studies, the prevalence of ACE varied from $11.8 \%$ for physical abuse to $61.8 \%$ for emotional neglect $[59,77]$. ACE as relevant risk factor for affective disorders $[13,34,36,37,40,47,75]$ was high in the present study population. Concerning response to antidepressant treatment Williams et al. [77] reported a significant prediction of response and remission to SSRI and SNRI treatment of sexual, physical and emotional abuse after 8 weeks of treatment with greater exposure leading to less response. The meta-analysis of Nanni et al. [58] also stated that patients with a history of childhood maltreatment benefit less from psychopharmacology, psychotherapy and combined therapy. Another study found that patients with multiple traumatisation or sexual abuse showed the worst response to psychotherapy treatment [66].

Considered as a very severe kind of traumatisation, the literature suggests that sexual abuse leaves the most lasting marks on the human body and soul $[11,16,56,66,77]$. As a possible conclusion, sexual abuse and multiple ACE could be considered as a relevant variable in treatment response. Nevertheless, we could not find any associations of specific forms of ACE and the response to anti-depressant treatment in this sample. The lack of a differentiate consideration of the treatment without a specific study protocol including pharmacological and non-pharmacological treatment implications could be an obvious explanation for this and is likely to be limiting for our findings. Nevertheless, specific treatment implications after ACE need further investigations. Besides psychopharmacology and psychotherapy, the treatment-setting itself could also play an important role. Emotionally neglected patients could maybe profit better from multimodal therapy settings; the face-to-face interpersonal experiences within the setting could be seen as an additional curative factor for people with unsatisfied attachment needs.

\section{hsCRP and depression}

So far, the discussion about inflammatory biomarkers in depression has not come to an end [27, 29, 55, 69, 81]. Patients with depressive symptoms are considered to show higher levels of pro-inflammatory cytokines and acutephase-proteins. The most investigated targets in the search for classifying and prognostic factors in current literature are IL-6, Il-1 $\beta$, TNF- $\alpha$ and hsCRP [81]. The latter represents a common final pathway as the response to rising levels of IL-6 and TNF- $\alpha$ [15]. HsCRP is well established as a laboratory marker, is simple and cheap to measure and shows the most robust associations with ACE [15, 81]. Nevertheless, in our study, patients with uni- and bipolar depression did not show significantly higher levels of hsCRP compared to healthy controls as described in other studies [15, 27]. While the means of the hsCRP levels in the study population lay above the levels of the healthy controls, the differences did not reach statistical significance. By contrast, a recent study by Moraes et al. [56] did not find serum hsCRP levels to differ from healthy controls either. For bipolar-depression, there is less data providing information about levels of hsCRP, furthermore the available data is heterogenous [65]. Still Wysokinski et al. [80] could not find significant differences of CRP levels in a large sample of inpatients suffering from acute schizophrenia, bipolar mania or bipolar depression.

Concerning hsCRP itself, the literature suggests that the inflammatory response represented by CRP can be helpful identifying subgroups of depressed patients (e.g., atypical vs. typical depression) [45], but is less suitable for characterizing general depression [81]. Therefore, and considering the complexity of the inflammation process itself and the development of depressive symptoms, our findings support the statement that relying on a single inflammation marker is not expedient (for a further overview see e.g. Ref. [81]). The associations of depression and hsCRP were namely reported to be consistent but small $(r=0.05)$ [32]. In the field of lowgrade inflammation, hsCRP appears to be very susceptible 
to confounders like e.g. age, sex, beginning infection, medication or the phase of a bipolar disorder [25, 32]. Concerning treatment response to antidepressant therapy however, inflammation markers are being discussed as having further clinical implications than for general characteristics of depression.

In contrast to our findings, recent literature identified higher levels of inflammation markers as being associated with treatment response $[12,71]$. In the present study, we could not find any associations between hsCRP levels and treatment response. Possible explanations may lie in the missing distinction of the anti-depressants used within the open-label design. Several studies have identified levels of inflammation markers to be predictive for better response when treatment occurs with specific anti-inflammatory treatment $[42,64]$ or when differentiating into different subgroups of antidepressants $[46,73]$. So, the response to antidepressant treatment is presumed to depend on baseline inflammation and the prescribed medication [5, 49]. Looking then at the trend of inflammation markers before and after anti-depressant treatment, Hiles et al. [31] found a normalisation of the measured biomarkers in most patients while another study found consistently high inflammation markers in patients who did not respond to antidepressant treatment [71].

While depressive symptoms significantly decreased over the study period, hsCRP levels did significantly increase during treatment. The MADRS and HAMD scores indicated only mild depressive symptoms after 6 weeks, whereas the BDI still indicated severe depression. This may be due to a subjective higher burden of the symptoms typical for depression in contrast to a more objective impression of a MADRS or HAMD rating. Conversely, the underlying immunological mechanisms and variations of inflammation markers in the treatment of depression are complex. Due to missing evidence, a substantiated statement concerning decrease or increase of hsCRP levels cannot be made so far [76]. To be able to make more precise statements concerning inflammation and specific treatment options in depression, further research is still needed.

\section{Limitations}

The findings of the present study have to be considered under certain limitations. In consideration of the complex question of this study, the population was comparatively small and bigger cohort would have been preferable. Compared to unipolar depression, the development of bipolar depression is considered to have additionally underlying mechanisms and genetic influences. As there is evidence for higher rates of ACE as well as higher levels of hsCRP in both uni- and bipolar depression, the analysis here appear reasonable. Additionally, the percentage of bipolar patients in this sample was low. Nevertheless, when searching for explanations for the origin of those diseases, separate models for each diagnosis may be more revealing.

Current research is looking for more individual and more specific psychopharmacological and psychotherapy treatment regimens to gain better response rates when treating depression. In our study, treatment was unspecified and probably represents a therapy regime which is widespread in psychiatry departments and according to clinical experience. But concerning the results for treatment response, the lack of a more differentiated analysis of the types and dosages of the medication applied surely limits the findings of the study. When looking for prognostic factors and biomarkers for depression, a differentiated consideration of different treatment arms dividing into psychotherapy and/ or varied drug regimens seems to be more conclusive to identify subgroups of depressed patients who might profit from a more personalised therapy. Besides the free choice of psychopharmacology during the study period, patients were also allowed to take any kind of medication without missing inclusion criteria at baseline. While current literature concerning the influences of anti-depressive medication on hsCRP is very heterogenous with recent articles reporting no significant influence on hsCRP, the missing effects of the prescribed medication at baseline on the inflammation marker needs further investigation. We excluded patients with a hsCRP level $>10 \mathrm{mg} / \mathrm{dl}$. As especially obese women can show hsCRP levels higher than $10 \mathrm{mg} / \mathrm{l}$ as a result of chronic inflammation [35] this may lead to a reduction of the variance in the present sample. Nevertheless, along with the most other studies in this field we stick to the recommendations of the U. S. Centers for Disease Control and Prevention and the American Heart Association which sets the hsCRP threshold for acute inflammation at $10 \mathrm{mg} / \mathrm{l}$. In numbers due to this limit, we excluded three patients whose hsCRP levels lay all above $20 \mathrm{mg} / \mathrm{dl}$. Furthermore, ACE were assessed via self-report-questionnaires which are known for a tendency towards underreporting. Especially when participants are suffering from major depression, a mood-bias is probable.

\section{Conclusion}

The present study emphasises an ongoing impact on inflammation regulation processes after specific forms of ACE. After correction for multiple testing, sexual abuse was associated with higher levels of hsCRP after the decline of the depressive symptoms in this uni- and bipolar sample. While emotional abused patients showed lower levels of hsCRP after the treatment period, we did not find any associations of ACE and hsCRP with the treatment response in the unipolar depressed subgroup in this study with its naturalistic 
design. As conducted in several other studies, in this context, we consider a more pre-defined study design with regard to medication and psychotherapy as more expedient. For future research and to reveal further clinical implications, the debate about biomarkers after ACE, the underlying mechanisms like e.g. epigenetic changes and biomarkers as a predictor for antidepressant treatment has to be continued, expanded and ideally brought together.

Authors' contributions All authors contributed to and have approved the final manuscript. All authors are entirely responsible for the scientific content; editing of language was assisted by Thelma Coutts.

Funding Open Access funding enabled and organized by Projekt DEAL.

Data availability Data are available from the Correspondence author.

Code availability Code is available from the Correspondence author; software application: SPSS 25.0

\section{Declarations}

Conflicts of interest All authors declare to have no conflicts of interest.

Ethics approval All procedures were approved by an independent local ethics committee and the study was conducted according to the criteria for Good Clinical Practice as well as to the Declaration of Helsinki in its last revision.

Consent to participate All authors gave written informed consent.

Consent for publication This article has not been published and is not under consideration for publication elsewhere.

Open Access This article is licensed under a Creative Commons Attribution 4.0 International License, which permits use, sharing, adaptation, distribution and reproduction in any medium or format, as long as you give appropriate credit to the original author(s) and the source, provide a link to the Creative Commons licence, and indicate if changes were made. The images or other third party material in this article are included in the article's Creative Commons licence, unless indicated otherwise in a credit line to the material. If material is not included in the article's Creative Commons licence and your intended use is not permitted by statutory regulation or exceeds the permitted use, you will need to obtain permission directly from the copyright holder. To view a copy of this licence, visit http://creativecommons.org/licenses/by/4.0/.

\section{References}

1. Aas M, Dieset I, Hope S, Hoseth E, Mørch R, Reponen E, Steen NE, Laskemoen JF, Ueland T, Aukrust P, Agartz I, Andreassen OA, Melle I (2017) Childhood maltreatment severity is associated with elevated C-reactive protein and body mass index in adults with schizophrenia and bipolar diagnoses. Brain Behav Immun 65:342-349
2. Aas M, Henry C, Andreassen OA, Bellivier F, Melle I, Etain B (2016) The role of childhood trauma in bipolar disorders. Int $\mathbf{J}$ Bipolar Disord 4(1):2

3. Afifi TO, Mather A, Boman J, Fleisher W, Enns MW, Macmillan H, Sareen J (2011) Childhood adversity and personality disorders: results from a nationally representative population-based study. $\mathbf{J}$ Psychiatr Res 45(6):814-822

4. Anda RF, Brown DW, Dube SR, Bremner JD, Felitti VJ, Giles WH (2008) Adverse childhood experiences and chronic obstructive pulmonary disease in adults. Am J Prev Med 34(5):396-403

5. Arteaga-Henriquez G, Simon MS, Burger B, Weidinger E, Wijkhuijs A, Arolt V, Birkenhager TK, Musil R, Muller N, Drexhage HA (2019) Low-grade inflammation as a predictor of antidepressant and anti-inflammatory therapy response in MDD patients: a systematic review of the literature in combination with an analysis of experimental data collected in the EU-MOODINFLAME consortium. Front Psychiatry 10:458

6. Baldwin JR, Arseneault L, Caspi A, Fisher HL, Moffitt TE, Odgers CL, Pariante C, Ambler A, Dove R, Kepa A, Matthews T, Menard A, Sugden K, Williams B, Danese A (2018) Childhood victimization and inflammation in young adulthood: a genetically sensitive cohort study. Brain Behav Immun 67:211-217

7. Baumeister D, Akhtar R, Ciufolini S, Pariante CM, Mondelli V (2016) Childhood trauma and adulthood inflammation: a metaanalysis of peripheral C-reactive protein, interleukin-6 and tumour necrosis factor-alpha. Mol Psychiatry 21(5):642-649

8. Beck AT, Steer RA, Carbin MG (1988) Psychometric properties of the beck depression inventory: twenty-five years of evaluation. Clin Psychol Rev 8(1):77-100

9. Bernstein DP, Fink L, Handelsman L, Foote J, Lovejoy M, Wenzel K, Sapareto E, Ruggiero J (1994) Initial reliability and validity of a new retrospective measure of child abuse and neglect. Am J Psychiatry 151(8):1132-1136

10. Bortolato M, Chen K, Shih JC (2008) Monoamine oxidase inactivation: from pathophysiology to therapeutics. Adv Drug Deliv Rev 60(13-14):1527-1533

11. Cattaneo A, Macchi F, Plazzotta G, Veronica B, Bocchio-Chiavetto L, Riva MA, Pariante CM (2015) Inflammation and neuronal plasticity: a link between childhood trauma and depression pathogenesis. Front Cell Neurosci 9:40

12. Chamberlain SR, Cavanagh J, de Boer P, Mondelli V, Jones DN, Drevets WC, Cowen PJ, Harrison NA, Pointon L, Pariante CM (2019) Treatment-resistant depression and peripheral C-reactive protein. Br J Psychiatry 214(1):11-19

13. Chapman DP, Whitfield CL, Felitti VJ, Dube SR, Edwards VJ, Anda RF (2004) Adverse childhood experiences and the risk of depressive disorders in adulthood. J Affect Disord 82(2):217-225

14. Choi J, Joseph L, Pilote L (2013) Obesity and C-reactive protein in various populations: a systematic review and meta-analysis. Obes Rev 14(3):232-244

15. Coelho R, Viola TW, Walss-Bass C, Brietzke E, Grassi-Oliveira R (2014) Childhood maltreatment and inflammatory markers: a systematic review. Acta Psychiatr Scand 129(3):180-192

16. Cummings M, Berkowitz SJ (2014) Evaluation and treatment of childhood physical abuse and neglect: a review. Curr Psychiatry Rep 16(1):429

17. Danese A, Moffitt TE, Harrington H, Milne BJ, Polanczyk G, Pariante CM, Poulton R, Caspi A (2009) Adverse childhood experiences and adult risk factors for age-related disease: depression, inflammation, and clustering of metabolic risk markers. Arch Pediatr Adolesc Med 163(12):1135-1143

18. Danese A, Moffitt TE, Pariante CM, Ambler A, Poulton R, Caspi A (2008) Elevated inflammation levels in depressed adults with a history of childhood maltreatment. Arch Gen Psychiatry 65(4):409-415 
19. de Punder K, Entringer S, Heim C, Deuter CE, Otte C, Wingenfeld K, Kuehl LK (2018) Inflammatory measures in depressed patients with and without a history of adverse childhood experiences. Front Psychiatry 9:610

20. Douglas KM, Porter RJ (2012) The effect of childhood trauma on pharmacological treatment response in depressed inpatients. Psychiatry Res 200(2-3):1058-1061

21. Dube SR, Anda RF, Felitti VJ, Edwards VJ, Croft JB (2002) Adverse childhood experiences and personal alcohol abuse as an adult. Addict Behav 27(5):713-725

22. Felitti VJ (2009) Adverse childhood experiences and adult health. Acad Pediatr 9(3):131-132

23. Felitti VJ, Anda RF (2010) The relationship of adverse childhood experiences to adult health, well-being, social function, and healthcare. The impact of early life trauma on health and disease the hidden epidemic. Cambridge University Press, Cambridge, UK

24. Felitti VJ, Anda RF, Nordenberg D, Williamson DF, Spitz AM, Edwards V, Koss MP, Marks JS (1998) Relationship of childhood abuse and household dysfunction to many of the leading causes of death in adults. The adverse childhood experiences (ACE) study. Am J Prev Med 14(4):245-258

25. Fernandes BS, Steiner J, Molendijk ML, Dodd S, Nardin P, Goncalves CA, Jacka F, Kohler CA, Karmakar C, Carvalho AF, Berk M (2016) C-reactive protein concentrations across the mood spectrum in bipolar disorder: a systematic review and meta-analysis. Lancet Psychiatry 3(12):1147-1156

26. Fryers T, Brugha T (2013) Childhood determinants of adult psychiatric disorder. Clin Pract Epidemiol Mental Health 9:1-50

27. Haapakoski R, Mathieu J, Ebmeier KP, Alenius H, Kivimaki M (2015) Cumulative meta-analysis of interleukins 6 and 1beta, tumour necrosis factor alpha and C-reactive protein in patients with major depressive disorder. Brain Behav Immun 49:206-215

28. Hamilton M (1960) A rating scale for depression. J Neurol Neurosurg Psychiatry 23(1):56

29. Hashimoto K (2015) Inflammatory biomarkers as differential predictors of antidepressant response. Int J Mol Sci 16(4):7796-7801

30. Herzog JI, Schmahl C (2018) Adverse childhood experiences and the consequences on neurobiological, psychosocial, and somatic conditions across the lifespan. Front Psychiatry 9:420

31. Hiles SA, Baker AL, de Malmanche T, Attia J (2012) Interleukin-6, C-reactive protein and interleukin-10 after antidepressant treatment in people with depression: a meta-analysis. Psychol Med 42(10):2015-2026

32. Horn SR, Long MM, Nelson BW, Allen NB, Fisher PA, Byrne ML (2018) Replication and reproducibility issues in the relationship between C-reactive protein and depression: a systematic review and focused meta-analysis. Brain Behav Immun 73:85-114

33. Huang H, Yan P, Shan Z, Chen S, Li M, Luo C, Gao H, Hao L, Liu L (2015) Adverse childhood experiences and risk of type 2 diabetes: a systematic review and meta-analysis. Metabolism 64(11):1408-1418

34. Infurna MR, Reichl C, Parzer P, Schimmenti A, Bifulco A, Kaess M (2016) Associations between depression and specific childhood experiences of abuse and neglect: a meta-analysis. J Affect Disord 190:47-55

35. Ishii S, Karlamangla AS, Bote M, Irwin MR, Jacobs DR Jr, Cho HJ, Seeman TE (2012) Gender, obesity and repeated elevation of C-reactive protein: data from the CARDIA cohort. PLoS ONE 7(4):e36062

36. Janiri D, Sani G, Danese E, Simonetti A, Ambrosi E, Angeletti G, Erbuto D, Caltagirone C, Girardi P, Spalletta G (2015) Childhood traumatic experiences of patients with bipolar disorder type I and type II. J Affect Disord 175:92-97
37. Jansen K, Cardoso TA, Fries GR, Branco JC, Silva RA, KauerSant'Anna M, Kapczinski F, Magalhaes PV (2016) Childhood trauma, family history, and their association with mood disorders in early adulthood. Acta Psychiatr Scand 134(4):281-286

38. Jiang S, Postovit L, Cattaneo A, Binder EB, Aitchison KJ (2019) Epigenetic modifications in stress response genes associated with childhood trauma. Front Psychiatry 10:808

39. Kessler RC, McLaughlin KA, Green JG, Gruber MJ, Sampson NA, Zaslavsky AM, Aguilar-Gaxiola S, Alhamzawi AO, Alonso J, Angermeyer M (2010) Childhood adversities and adult psychopathology in the WHO world mental health surveys. Br J Psychiatry 197(5):378-385

40. Kessler RC, McLaughlin KA, Green JG, Gruber MJ, Sampson NA, Zaslavsky AM, Aguilar-Gaxiola S, Alhamzawi AO, Alonso J, Angermeyer M, Benjet C, Bromet E, Chatterji S, de Girolamo G, Demyttenaere K, Fayyad J, Florescu S, Gal G, Gureje O, Haro JM, Hu CY, Karam EG, Kawakami N, Lee S, Lepine JP, Ormel J, Posada-Villa J, Sagar R, Tsang A, Ustun TB, Vassilev S, Viana MC, Williams DR (2010) Childhood adversities and adult psychopathology in the WHO world mental health surveys. Br J Psychiatry 197(5):378-385

41. Kittleson MM, Meoni LA, Wang N-Y, Chu AY, Ford DE, Klag MJ (2006) Association of childhood socioeconomic status with subsequent coronary heart disease in physicians. Arch Intern Med 166(21):2356-2361

42. Köhler O, Benros ME, Nordentoft M, Farkouh ME, Iyengar RL, Mors O, Krogh J (2014) Effect of anti-inflammatory treatment on depression, depressive symptoms, and adverse effects: a systematic review and meta-analysis of randomized clinical trials. JAMA Psychiatry 71(12):1381-1391

43. Kühner C, Bürger C, Keller F, Hautzinger M (2007) Reliability and validity of the revised beck depression inventory (BDI-II) results from German samples. Nervenarzt 78(6):651-656

44. Labonté B, Suderman M, Maussion G, Navaro L, Yerko V, Mahar I, Bureau A, Mechawar N, Szyf M, Meaney MJ (2012) Genomewide epigenetic regulation by early-life trauma. Arch Gen Psychiatry 69(7):722-731

45. Lamers F, Vogelzangs N, Merikangas KR, de Jonge P, Beekman AT, Penninx BW (2013) Evidence for a differential role of HPAaxis function, inflammation and metabolic syndrome in melancholic versus atypical depression. Mol Psychiatry 18(6):692-699

46. Lanquillon S, Krieg JC, Bening-Abu-Shach U, Vedder H (2000) Cytokine production and treatment response in major depressive disorder. Neuropsychopharmacology 22(4):370-379

47. Leclerc E, Mansur RB, Grassi-Oliveira R, Cordeiro Q, Kapczinski F, McIntyre RS, Brietzke E (2018) The differential association between history of childhood sexual abuse and body mass index in early and late stages of bipolar disorder. J Affect Disord 227:214-218

48. Lin JE, Neylan TC, Epel E, O'Donovan A (2016) Associations of childhood adversity and adulthood trauma with C-reactive protein: a cross-sectional population-based study. Brain Behav Immun $53: 105-112$

49. Liu JJ, Wei YB, Strawbridge R, Bao Y, Chang S, Shi L, Que J, Gadad BS, Trivedi MH, Kelsoe JR, Lu L (2020) Peripheral cytokine levels and response to antidepressant treatment in depression: a systematic review and meta-analysis. Mol Psychiatry 25(2):339-350

50. McGowan PO, Sasaki A, D'alessio AC, Dymov S, Labonté B, Szyf M, Turecki G, Meaney MJ (2009) Epigenetic regulation of the glucocorticoid receptor in human brain associates with childhood abuse. Nat Neurosci 12(3):342

51. Mehta D, Klengel T, Conneely KN, Smith AK, Altmann A, Pace TW, Rex-Haffner M, Loeschner A, Gonik M, Mercer KB (2013) Childhood maltreatment is associated with distinct genomic and 
epigenetic profiles in posttraumatic stress disorder. Proc Natl Acad Sci 110(20):8302-8307

52. Miller AH, Raison CL (2016) The role of inflammation in depression: from evolutionary imperative to modern treatment target. Nat Rev Immunol 16(1):22-34

53. Monnat SM, Chandler RF (2015) Long-term physical health consequences of adverse childhood experiences. Sociol Q 56(4):723-752

54. Montgomery SA, Åsberg M (1979) A new depression scale designed to be sensitive to change. Br J Psychiatry 134(4):382-389

55. Mora C, Zonca V, Riva MA, Cattaneo A (2018) Blood biomarkers and treatment response in major depression. Expert Rev Mol Diagn 18(6):513-529

56. Moraes JB, Maes M, Barbosa DS, Ferrari TZ, Uehara MKS, Carvalho AF, Nunes SOV (2017) Elevated C-reactive protein levels in women with bipolar disorder may be explained by a history of childhood trauma, especially sexual abuse, body mass index and age. CNS Neurol Disord Drug Targets 16(4):514-521

57. Muller N, Krause D, Barth R, Myint AM, Weidinger E, Stettinger W, Zill P, Drexhage H, Schwarz MJ (2019) Childhood adversity and current stress are related to pro- and anti-inflammatory cytokines in major depression. J Affect Disord 253:270-276

58. Nanni V, Uher R, Danese A (2012) Childhood maltreatment predicts unfavorable course of illness and treatment outcome in depression: a meta-analysis. Am J Psychiatry 169(2):141-151

59. Nemeroff CB (2004) Neurobiological consequences of childhood trauma. J Clin Psychiatry 65(Suppl 1):18-28

60. Nemeroff CB (2016) Paradise lost: the neurobiological and clinical consequences of child abuse and neglect. Neuron 89(5):892-909

61. Nusslock R, Miller GE (2016) Early-life adversity and physical and emotional health across the lifespan: a neuroimmune network hypothesis. Biol Psychiatry 80(1):23-32

62. Paquola C, Bennett MR, Lagopoulos J (2016) Understanding heterogeneity in grey matter research of adults with childhood maltreatment-a meta-analysis and review. Neurosci Biobehav Rev 69:299-312

63. Quide Y, Bortolasci CC, Spolding B, Kidnapillai S, Watkeys OJ, Cohen-Woods S, Berk M, Carr VJ, Walder K, Green MJ (2018) Association between childhood trauma exposure and pro-inflammatory cytokines in schizophrenia and bipolar-I disorder. Psychol Med 49(16):2736-2744

64. Raison CL, Rutherford RE, Woolwine BJ, Shuo C, Schettler P, Drake DF, Haroon E, Miller AH (2013) A randomized controlled trial of the tumor necrosis factor antagonist infliximab for treatment-resistant depression: the role of baseline inflammatory biomarkers. JAMA Psychiatry 70(1):31-41

65. Sayana P, Colpo GD, Simoes LR, Giridharan VV, Teixeira AL, Quevedo J, Barichello T (2017) A systematic review of evidence for the role of inflammatory biomarkers in bipolar patients. J Psychiatr Res 92:160-182

66. Schilling C, Weidner K, Schellong J, Joraschky P, Pohlmann K (2015) Patterns of childhood abuse and neglect as predictors of treatment outcome in inpatient psychotherapy: a typological approach. Psychopathology 48(2):91-100

67. Schmidtke A, Fleckenstein P, Moises W, Beckmann H (1988) Studies of the reliability and validity of the German version of the Montgomery-Asberg depression rating scale (MADRS). Schweiz Arch Neurol Psychiatr (Zurich, Switzerland: 1985) 139(2):51-65

68. Shamseddeen W, Asarnow JR, Clarke G, Vitiello B, Wagner KD, Birmaher B, Keller MB, Emslie G, Iyengar S, Ryan ND, McCracken JT, Porta G, Mayes T, Brent DA (2011) Impact of physical and sexual abuse on treatment response in the treatment of resistant depression in adolescent study (TORDIA). J Am Acad Child Adolesc Psychiatry 50(3):293-301

69. Smith KJ, Au B, Ollis L, Schmitz N (2018) The association between C-reactive protein, interleukin-6 and depression among older adults in the community: a systematic review and metaanalysis. Exp Gerontol 102:109-132

70. SPSS Inc. (2017) IBM SPSS 250 for windows [computer software]. SPSS Inc., IL

71. Strawbridge R, Arnone D, Danese A, Papadopoulos A, Herane Vives A, Cleare AJ (2015) Inflammation and clinical response to treatment in depression: a meta-analysis. Eur Neuropsychopharmacol 25(10):1532-1543

72. Topitzes J, Mersky JP, Reynolds AJ (2010) Child maltreatment and adult cigarette smoking: a long-term developmental model. J Pediatr Psychol 35(5):484-498

73. Uher R, Tansey KE, Dew T, Maier W, Mors O, Hauser J, Dernovsek MZ, Henigsberg N, Souery D, Farmer A, McGuffin P (2014) An inflammatory biomarker as a differential predictor of outcome of depression treatment with escitalopram and nortriptyline. Am J Psychiatry 171(12):1278-1286

74. Valkanova V, Ebmeier KP, Allan CL (2013) CRP, IL-6 and depression: a systematic review and meta-analysis of longitudinal studies. J Affect Disord 150(3):736-744

75. Watson S, Gallagher P, Dougall D, Porter R, Moncrieff J, Ferrier IN, Young AH (2014) Childhood trauma in bipolar disorder. Aust N Z J Psychiatry 48(6):564-570

76. Wiedlocha M, Marcinowicz P, Krupa R, Janoska-Jazdzik M, Janus M, Debowska W, Mosiolek A, Waszkiewicz N, Szulc A (2018) Effect of antidepressant treatment on peripheral inflammation markers - a meta-analysis. Prog Neuropsychopharmacol Biol Psychiatry 80(Pt C):217-226

77. Williams LM, Debattista C, Duchemin AM, Schatzberg AF, Nemeroff CB (2016) Childhood trauma predicts antidepressant response in adults with major depression: data from the randomized international study to predict optimized treatment for depression. Transl Psychiatry 6:e799

78. Wingenfeld K, Spitzer C, Mensebach C, Grabe HJ, Hill A, Gast U, Schlosser N, Höpp H, Beblo T, Driessen M (2010) Die deutsche version des childhood trauma questionnaire (CTQ): erste befunde zu den psychometrischen kennwerten. Psychother Psych Med 60(11):442-450

79. Wium-Andersen MK, Orsted DD, Nielsen SF, Nordestgaard BG (2013) Elevated C-reactive protein levels, psychological distress, and depression in 73, 131 individuals. JAMA Psychiatry 70(2):176-184

80. Wysokinski A, Margulska A, Strzelecki D, Kloszewska I (2015) Levels of C-reactive protein (CRP) in patients with schizophrenia, unipolar depression and bipolar disorder. Nord J Psychiatry 69(5):346-353

81. Young JJ, Silber T, Bruno D, Galatzer-Levy IR, Pomara N, Marmar CR (2016) Is there progress? An overview of selecting biomarker candidates for major depressive disorder. Front Psychiatry 7:72

82. Yu M, Linn KA, Shinohara RT, Oathes DJ, Cook PA, Duprat R, Moore TM, Oquendo MA, Phillips ML, McInnis M, Fava M, Trivedi MH, McGrath P, Parsey R, Weissman MM, Sheline YI (2019) Childhood trauma history is linked to abnormal brain connectivity in major depression. Proc Natl Acad Sci USA 116(17):8582-8590

83. Zannas AS, Jia M, Hafner K, Baumert J, Wiechmann T, Pape JC, Arloth J, Kodel M, Martinelli S, Roitman M, Roh S, Haehle A, Emeny RT, Iurato S, Carrillo-Roa T, Lahti J, Raikkonen K, Eriksson JG, Drake AJ, Waldenberger M, Wahl S, Kunze S, Lucae S, Bradley B, Gieger C, Hausch F, Smith AK, Ressler KJ, MullerMyhsok B, Ladwig KH, Rein T, Gassen NC, Binder EB (2019) Epigenetic upregulation of FKBP5 by aging and stress contributes to NF-kappaB-driven inflammation and cardiovascular risk. Proc Natl Acad Sci USA 116(23):11370-11379 